shock and raise fears about dangerousness seem clear. It is particularly concerning when they occur in journals aimed at a wide variety of health professionals in a way likely to reinforce preexisting negative stereotypes about the mentally ill.

Mental health care organisations are striving to take on board high quality risk management and evidence based strategies in planning care for the severely mentally ill and advertising gimmicks that owe more to Poe and Hitchcock than to an informed balanced view of mental illness appeal to the irrational antithesis of this approach. It is not much of a partnership if drug companies use adverts that would cause distress to anyone suffering from schizophrenia or members of their families.

C. J. Haley Locum Consultant Psychiatrist, Primary Care Mental HealthTeam, University Hospital Aintree, 46 Moss Lane, Liverpool L9 8AL

\section{Urinary detection of olanzapine - an aid to compliance confirmed}

Sir: The recent introduction of this technique (Coates, 1999) has led to an important development in psychiatric practice in our area, with possible national consequences.

At a recent mental health review tribunal, due to the fact that a patient had consistently tested negative for olanzapine it was accepted that the patient was not adherent with treatment, contrary to their assertion. The presence of objective evidence of nonadherence was, I believe, instrumental in the tribunal's decision to continue a detention order. Therefore, this shows that there are considerable implications of regular testing for olanzapine, and possibly other antipsychotics, in urine. Within the context of judicial or semijudicial processes, objectively testable evidence will, I believe, always have a greater weight than that of subjective opinion. I therefore believe that urinary detection of olanzapine has been confirmed as an aid to adherence. The issue of whether adherence then becomes compulsion is something that will require further consideration.

COATES, J. (1999) Urinary detection of olanzapine an aid to compliance. British Journal of Psychiatry, 175, 591-592.

John W. Coates Consultant Psychiatrist, Rotherham General Hospital, Moorgate Road, Rotherham, South Yorkshire S60 2UD

\section{Pre-registration training period in psychiatry}

Sir: There may be benefit in the approval and funding of pre-registration posts in specialities other than general medicine and surgery. Indeed a number of posts in general practice have existed for some time.

A recent report by the Royal College of Physicians of London (2000), published on-line, describes "shortening formal training of medical students to four years, and extending pre-registration training to two years", and that the "senior house officer grade should be better linked to opportunities for training in primary care".

These suggestions may also be useful for psychiatric practice, where an increasing throughput of patients, and the need for senior house officer educational time, are putting pressure on services. A pre-registration period spent working in psychiatry should be of training value to those pursuing a career in many different specialities, and closer liaison with general practice in senior house officer training helped by the formation of primary care trusts.

ROYAL COLLEGE OF PHYSICIANS OF LONDON (2000) Hospital Doctors Under Pressure: New Roles for the Health CareWorkforce. http:// www.rcplondon.ac.uk/pubs/wp.hdup.htm

Stephen Carey Specialist Registrar in Psychiatry, Crighton Royal Hospital, Dumfries DG1 4TG: stephencarey@rathcar.freeserve.co.uk

\section{Histories and mental states: from standard formats to standard forms?}

Sir: Kareem \& Ashby (Psychiatric Bulletin, March 2000, 24, 109-110) moot the possibility of a definite Mental State Examination (MSE) format in order to decrease the chances of important items being unexamined or unrecorded. This seems reasonable, but there may be difficulties as our experience auditing alcohol history-taking in the elderly shows.

We audited the alcohol histories recorded for all the elderly patients in Fair Mile Hospital. We found 147 new assessments. Of these, 81 (55\%) failed to record an alcohol history, 37 (25\%) recorded a qualitative history and only $29(20 \%)$ recorded the number of units drunk. Where a history proforma was used the alcohol histories were better. We developed a pro forma for the history and MSE, which included a reminder to record units of alcohol. Having piloted the pro forma, it was introduced for general use and, following educational sessions devoted to alcohol problems in the elderly, notes were re-audited six months later.

In the second audit, when the pro forma was used, only $11 \%$ failed to record an alcohol history, whereas 33\% recorded qualitative and $55 \%$ quantitative histories. This was a statistically significant improvement $\left(P<0.02 ; \chi^{2}\right.$ test with Yates's correction, d.f. $=1)$. But the pro forma was used in only nine out of 74 new assessments! Overall the alcohol history-taking had not improved $(P<0.5$; $\chi^{2}$ test, d.f. $=2$ )

Part of the problem was simply logistical: the pro forma was not readily available. But there was also a reluctance to use it. There was a concern that it made history-taking and the MSE less natural. Of course, such a pro forma does not have to be slavishly completed at the time of the history and MSE. Nevertheless, there are important issues involved in the use of such a pro forma which are worthy of further consideration.

*Julian C. Hughes Consultant Psychiatrist, Gibside Unit, Centre for the Health of the Elderly, Newcastle General Hospital, Westgate Road, Newcastle uponTyne NE4 6BE, Jonathan M. Griffiths Senior House Officer, Jaap van der Boom Senior House Officer. Formerly of the Department of Old Age Psychiatry, Fair Mile Hospital, Cholsey, Oxfordshire 